\title{
TraduZIR O INTRADUZÍveL \\ o impacto dos textos sagrados orientais \\ no Ocidente
}

\author{
F. D. Santos* \\ Universidade Federal de Minas Gerais - Fapemig
}

\begin{abstract}
RESUMO
As obras do remoto Oriente foram trazidas para a Europa ao longo dos séculos XVIII e XIX para serem estudadas inicialmente com intenção polêmica, visando fortalecer as crenças coloniais na superioridade ocidental. Porém o seu estudo tomou caminhos imprevisíveis, colocando em causa a identidade religiosa e cultural da Europa dominante e as crenças religiosas dos conquistadores. No final a cultura do vencido acabou conquistando a do arrogante vencedor, segundo o paradigma horaciano (Hor., Epistulae 2.1.156-7). Um novo mundo "antigo" surge ante os olhos estupefatos dos homens de pensamento, um mundo cuja pervivência poderia e deveria ser estudada in situ. Deu-se uma revolução cultural tão importante como a provocada pelo renascimento da cultura greco-latina e a descoberta de novos continentes e populações no século XV, ou a dos novos mundos astronômicos, físicos e da história natural ao longo da Idade Moderna. As principais consequências da vitória da Filologia se fizeram sentir no mundo da teologia e da filosofia.
\end{abstract}

\section{PALAVRAS - CHAVE}

Orientalismo, Gramática comparada, Tradução

mundo romano-cristão fora um mundo culturalmente fechado pelo perímetro muçulmano, que lhe formou um cerco só rompido pelas navegações atlânticas e índicas do século XV rumo aos mercados e produtos asiáticos. Se é certo que o Islã influenciara profundamente a literatura europeia, o seu pensamento e sobretudo a sua filosofia, já esses novos contatos com os povos ameríndios e subsaarianos, de culturas majoritariamente ágrafas ou "pós-gráficas", ${ }^{1}$ não suscitaram revelações no domínio da literatura religiosa, com a possível exceção da literatura abissínia e de alguns textos mesoamericanos, estes últimos não fornecendo materiais sobre religiões vivas, mas tão somente vestígios de

\footnotetext{
*filipe.delfim@gmail.com

${ }^{1}$ Suas escritas tendo caído em desuso, como os silabários gregos da época homérica.
} 
crenças moribundas. Seriam as conquistas europeias sobre a Índia e a China que iriam por fim desvelar ao mundo ocidental novos textos de inspiração profética, filosófica e poética, cuja antiguidade iria desafiar a dos textos bíblicos, então considerados o fundamento da espiritualidade europeia.

A febre dos textos sagrados chineses e indianos mobilizou na época quase todas as nações ocidentais com um afã só antes visto em tempos do Renascimento Greco-latino. O novo Renascimento Oriental foi um movimento cultural igualmente amplo, com ramificações das artes às letras, do pensamento à arquitetura, da política às ciências. Se o Renascimento do Mundo Antigo fora iniciado na Florença de quatrocentos com o resgate dos textos herméticos, dos Oráculos Caldaicos e do corpus platônico, mediados pela leitura dos mestres neoplatônicos que apresentaram Platão aos modernos - Jâmblico e Proclo -, o novo Renascimento buscaria também desvelar tradições sagradas, sapiências secretas transmitidas em círculos iniciáticos, obras transmitidas através de longas linhagens discipulares. Tal como então, iria brilhar o pioneirismo de tradutores de prodigiosa capacidade de trabalho e de assombroso talento poliglota; e em ambos os renascimentos assistimos a uma exigência crescente de manuscritos mais completos e mais fiáveis, uma corrida à primazia editorial, à febre das descobertas, ao patrocínio dos poderosos, à mobilização de meios financeiros vultuosos para uma aventura prestigiante e intelectualmente compensadora, ainda que de consequências imprevisíveis...

\section{Ex OrIENTE LuX}

Para definir o conceito de "textos sagrados orientais" é necessário determinar o que nele se pode incluir. Os critérios de sacralização de um texto não são internos, porque não são temáticos (de assunto), nem estilísticos, porque não há um estilo comum ou uma retórica própria, ainda que frequentemente se detectem recursos mnemónicos destinados a favorecer a sua transmissão oral; tampouco estes textos partilham as convenções de um gênero específico pois todos os gêneros são contemplados, desde a crônica ao hino, do conto aos aforismos, do drama à epopeia. Os critérios de sacralização dos textos são antes totalmente externos, e sumarizam-se em três: autoria, uso ritual e consagração pela tradição. Por "autoria" de um texto sagrado entende-se a sua atribuição a um profeta, a um vidente ou a um escolarca de uma linhagem filosófica, ou ainda a uma divindade, com transmissão mais ou menos direta, desde o "ditado" à "inspiração profética"; ou ele pode também ser creditado a um sacerdote ou a um fundador/reformador de religião. Por "uso" entende-se que este texto seja empregue em cerimônias religiosas de caráter sacerdotal, recitado perante as imagens divinas, preservado e transmitido em templos (as tábuas mosaicas são exemplo de um texto para a guarda do qual se construiu um templo). A "consagração" da sacralidade de um escrito é a existência de uma tradição coerente, oral e/ou escrita, confirmando esse estatuto "sagrado" - termo derivado do lat. sacrum e significando tabu, ou seja, "proibido aos profanos", daí obtendo estatuto de "semi-secreto". A sacralidade de um texto contém ainda as implicações de "inalterável", "incriticável", por vezes "incompreensível", e assim radicalmente intraduzível na sua dignidade original. As três categorias nem sempre se aplicam em simultâneo aos livros que o Ocidente acabou considerando como sagrados, e que são tão diversos entre si como foram diversas as culturas 
e as épocas que os produziram. Enumerando essas tradições pela ordem do seu impacto sobre a Europa constataremos que em primeiro lugar chegaram os clássicos chineses confucianos e taoistas; depois as sentenças de Zaratustra, seguidas pelos escritos pós-védicos indianos, ou seja, os upanishádicos e os purânicos; vieram depois os tratados e sermões budistas e por fim os conjuntos de textos chamados propriamente védicos, os mais antigos da Índia.

$\mathrm{Na}$ Europa o conceito de texto sagrado era não só importado como recente: se no Egito as fórmulas e orações gravadas e pintadas nos templos, sepulturas e múmias já possuíam esse estatuto, o mundo greco-romano não produziu "textos sagrados" propriamente ditos. As religiões do mundo antigo antedatavam os seus próprios sistemas de escrita, não tinham fundador individual nem assentavam em uma revelação inicial. A transmissão de hinos e fórmulas era feita por via oral. É certo que surgiram textos sectários dos pitagóricos com algum estatuto de sacralidade, ou os tratados herméticos do Egito greco-romano, ou ainda os já referidos Oráculos Caldaicos, aos quais os filósofos neoplatônicos reformadores do Helenismo deram a maior atenção considerando-os textos inspirados e revelados, capazes de vivificar a espiritualidade helênica.

Foi após o florescimento das religiões grega e romana, anistóricas, que apareceram as religiões "cronísticas", fundadas em um evento suscitador de um relato, de uma narrativa. Esta podia pertencer ao gênero biográfico, produzindo um "biotexto", ou então reproduzir os ensinamentos orais do fundador da doutrina (os ditos de Zaratustra, os sermões do Buda, etc.). As religiões históricas de fundadores individuais se opunham assim enquanto "religiões de livros" às anteriores "religiões de récitas", que usavam textos rituais e mágicos: hinos, mantras, orações, etc. ${ }^{2}$ No espaço de um século, entre meados do século VI e do V a.C., em plena expansão dos sistemas de escrita, surgiram as personalidades vigorosas de Buda, Mahavira, Confúcio, Lao-Tse, Pitágoras e também Zaratustra, o primeiro dos reformadores de um culto tradicional, no seu caso o mazdeísmo. ${ }^{3}$

$\mathrm{Na}$ longa recepção de dois séculos do Renascimento Oriental não prevaleceu um conceito rígido e uniforme de "texto sagrado". Os orientalistas classificavam por analogia os textos que lhes iam chegando: atribuíam o estatuto de "sagrados" aos que apresentavam algumas características internas comuns àqueles que na tradição europeia eram já conhecidos como tais, ou seja, os pertencentes à grande variedade de gêneros contida nos textos bíblicos ou então ao mais uniforme Corão. O estatuto de "sagrado" na teologia europeia conhecia diferentes gradações: os teólogos cristãos separavam os escritos canônicos dos deuterocanónicos e subalternizavam os pseudepígrafos, os apócrifos e os gnósticos (ou "secretos", que tinham um caráter sectário comparável ao do movimento tântrico no hinduísmo e no budismo). O sistema bramânico também usava uma complexa hierarquia:

\footnotetext{
${ }^{2}$ A oração do "pater nostrum" inserida nos evangelhos é um resquício formulaico da antiga mentalidade.

${ }^{3}$ As reformas das religiões aparecem ligadas à época da expansão da escrita: o taoísmo pode ser interpretado como uma reforma do confucionismo, o cristianismo uma reforma do judaísmo, o maniqueísmo seria a reforma do cristianismo e o Islã foi uma reforma simultânea do cristianismo e do judaísmo; o budismo visara inicialmente à reforma do bramanismo, mas na sua fase inicial logo multiplicou tanto seus próprios escritos e testemunhos que é chamado não de religião "do livro" mas "de biblioteca", com sua infinidade de textos de desigual tamanho - embora de igual importância para os seus seguidores. Por sua vez, o cristianismo substituiu o antigo formato do rolo, o uolumen, pelo novo codex, o caderno, e foi a industrialização deste último, graças aos tipos móveis metálicos de Gutenberg, que possibilitou o acesso universal à Bíblia e serviu de base à reforma protestante.
} 
os seus textos dividiam-se em sacratíssimos ou sacerdotais (começando pelos hinos dos Vedas, da raiz -vid, "conhecimento", e que são em número de 4, ou melhor, de 3+1 - os sacrificiais Rig, Yajur, Sama e o Atharva que recolhe fórmulas mágicas); por sua vez estas coletâneas litúrgicas são completadas por comentários, os brahmanas, e pelos debates especulativos contidos nas exegeses, as upanishadas. É este conjunto que compõe a sruti, ou "textos ouvidos", que não provêm dos deuses e sim daquilo que há de divino nos homens, tendo sido escutados em profunda meditação pelos rishi, os videntes da antiga Índia, sendo depois passados a escrito. O nível de sacralização descendente é composto pelos textos smriti, ou textos "memorizados". Estes se destinam não aos sacerdotes e sim ao povo: é um grupo que engloba os itihasas (novelas ou epopeias: o Mahabharata, o Ramayana e o Harivamsa) e também os inúmeros puranas (mitos), que tratam temas equiparáveis aos da Bíblia judaica: criação, destruição e renovação do mundo, genealogia dos deuses e patriarcas, crônica dos reis de raça solar e lunar. Também a tradição esotérica indiana possui seus escritos diferenciados que incluem os nigamas, agamas, yamalas e os tantras; estes são geralmente diálogos que reproduzem colóquios filosóficos entre o deus Shiva e sua consorte Shakti.

\section{Nada há de mais Visível do que aquilo que é SeCreto ${ }^{4}$}

Totalmente diferentes são os clássicos confucianos: o grupo dos Seis Clássicos é na verdade pré-confuciano e foi adotado como cânone pela escola confuciana de pedagogia e filosofia: Shih Ching ou "O Livro da Poesia" (coletânea poética); Shu Ching ou "O Livro da História" (editos reais); I Li ou "Os Rituais" (cerimônias e conduta quotidiana); I Ching ou "O Livro das Mutações" (adivinhação da evolução cósmica e social pelo método do octograma); Yueh Ching ou o "Livro da Música" (hoje perdido); e Ch'un Ch'iu, "Os Anais da Primavera e do Outono". Um outro conjunto de consagração tardia e de redação pós-confuciana é o dos Quatro Livros que registram, esses sim, as opiniões e as lições do Mestre Confúcio: Ta Hsueh ou "A Educação Superior"; Chung Yung ou "A Doutrina do Equilíbrio", Lun Yu ou "Os Analectos"; e Meng-tzu, ou o "Mencius".5

O Tao Te Ching, ou "O Livro do Percurso Virtuoso", atribuído ao Mestre Lao-Tsé, é uma obra moral equiparável aos Versos de Ouro dos pitagóricos. As orações de Zaratustra são do mesmo modo injunções morais. Os tratados budistas consistem num sermonário de palestras e de relatos mais ou menos biografados de diálogos edificantes, como os que se encontram mais tarde nos Evangelhos. No Japão, onde as tradições do shinto e as animistas se combinaram harmoniosamente com o budismo e o confucionismo, o Ocidente não reconheceu textos sagrados de estatuto semelhante aos dos chineses, persas ou indianos. Mas os Nihongi ou "Anais Imperiais", e os Kojiki ou "Livros mitológicos”, similares aos escritos purânicos, foram traduzidos na Europa no final do século XIX, tal como as recolhas das lendas de caráter mais ou menos religioso dos Ainu, os aborígenes pré-nipônicos do Japão.

\footnotetext{
${ }^{4}$ Chung Yung, 1.3.

${ }^{5}$ Para a complexa formação do cânone confuciano: JINGPAN. Confucius as a Teacher. Beijing, p. 122-170.
} 


\section{A COLONIZAÇÃO DITANDO A AGENDA FILOLÓGICA: GRAMÁTICA E COLONIALISMO}

Um dos momentos críticos do assalto europeu ao mundo dos textos asiáticos foi a publicação em 1816 do Système de la conjugaison du sanscrit comparé avec celui des langues grecque, latine, persane et germanique de Franz Bopp, que fundou uma extensa linhagem de gramáticas comparadas. ${ }^{6}$ A colonização cultural seguia as vicissitudes políticas: os ingleses, e logo após os alemães, se devotaram ao estudo do sânscrito e dos textos indianos, enquanto os franceses, afastados do subcontinente sul-asiático, se concentravam nos textos persas e nos chineses. A motivação colonial que subjazia a muitos tradutores derivava de seu proselitismo cristão e do desejo de "colonização espiritual" do Oriente. Para eles a "conversão dos gentios" operada pelos missionários seria facilitada pela refutação "filológica" dos "mitos pueris" que sustentavam as "religiões decadentes", 7 expondo seus textos ao ridículo com as traduções para as línguas europeias.

As traduções iniciais não tinham puras finalidades filológicas ou científicas, elas eram muitas vezes o trabalho de sacerdotes e missionários cristãos e eram entendidas como um instrumento para a apropriação, colonização e cristianização do Oriente. Entre os maiores atores desse jogo há que nomear a Companhia de Jesus e a Companhia das Índias, ambas datadas do século XVI, mas que iriam conhecer sua maior expansão durante o século XVII. Elas foram Estados sem nações, com um poder transnacional que lhes permitiu enfrentar e sobrepujar todas as potências de sua época. A Companhia de Jesus foi a primeira instituição a promover de forma organizada as traduções dos escritos chineses para latim, então língua franca da Europa culta. E a Companhia das Índias britânica seguiu os mesmos passos, promovendo traduções de textos indianos, no seu caso para o inglês. Podemos diferenciar as seguintes gerações de tradutores, ainda que por vezes elas se encontrem sobrepostas: os missionários jesuítas no Oriente; os funcionários coloniais ao serviço da East India Co.; as academias reais e os seus membros; os eruditos das sociétés savantes coloniais e metropolitanas; os universitários nas suas recém-criadas cátedras de orientalística; alguns aventureiros, viajantes ou entusiastas por conta própria.

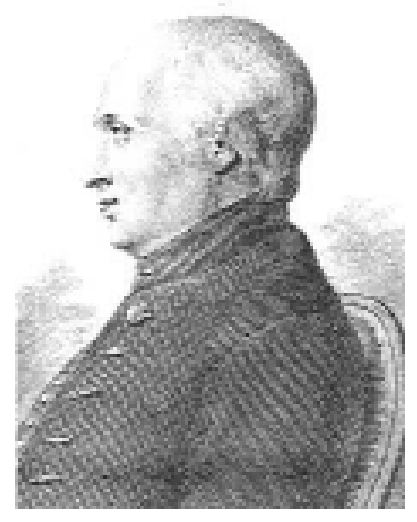

Anquetil-Duperron

\footnotetext{
${ }^{6}$ Os orientalistas não deixarão também de ser influenciados pelos sucessos científicos da exploração do Egito por parte dos estudiosos que acompanharam Napoleão, e pelas subsequentes descobertas de Champollion no domínio da arqueolinguística egípcia a partir de 1822, ano em que escreveu a Lettre à M. Dacier relative à l'alphabet des hiéroglyphes phonétiques, aliás o mesmo ano dos Éléments de grammaire chinoise d'Abel Rémusat.
}

${ }^{7}$ Expressões usadas por Max Müller. 
É precisamente nesta última categoria que encontramos um dos primeiros orientalistas franceses: Abraham Hyacinthe Anquetil-Duperron, 1731-1805. Ao tomar conhecimento dos textos parsi ele desistiu de seus estudos de hebraico e com apenas 23 anos viajou para a Índia (tendo de se alistar na marinha francesa, pois não tinha dinheiro para pagar a viagem). Aí viveu durante seis anos para aprender o persa, o sânscrito, o avesta e o pahlavi. Forçado a regressar à França pelos avanços das conquistas inglesas, levou consigo 180 manuscritos que doou à Biblioteca Real. Em 1771 publicou em três volumes a sua tradução do Zend-Avesta, apresentando o zoroastrismo pela primeira vez à Europa. Também traduziu as Upanishadas para latim em 1804. Entre muitas outras obras que escreveu conta-se o relato autobiográfico da sua acidentada viagem em que quase perdeu a vida. ${ }^{8}$

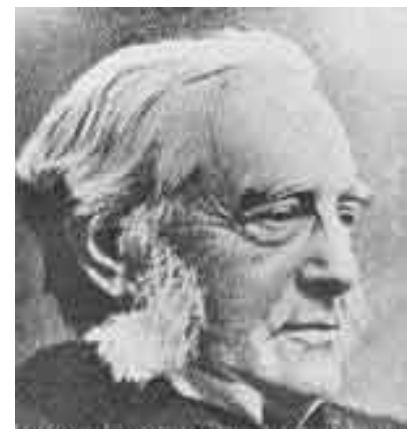

Friedrich Max Müller

Max Müller foi funcionário da East India e incansável editor dos 50 volumes dos Sacred Books of the East. Ele nasceu em 1823 e também emigrou com 23 anos, em seu caso da Alemanha para a Inglaterra, pelas mesmas razões que tinham levado Anquetil-Duperron a fugir da Índia: o domínio colonial inglês sobre o subcontinente tornava a Grã-Bretanha um local de trabalho ideal para um indólogo. De 1849 a 1874 a Companhia das Índias contratou e pagou regiamente o trabalho de Max Müller para a edição crítica dos Vedas. Em 1851 ele proferiu as suas conferências sobre Filologia Comparada, abrindo caminho para a conquista da cátedra em Oxford em 1854. Se em 1860 perdeu o concurso para a cátedra de Sânscrito, conseguiu oito anos depois vir a ser o primeiro professor de Teologia Comparada em Oxford (1868-1875). ${ }^{9}$ Idolatrado por alguns indianos, que o viam como "apóstolo" da cultura védica no Ocidente, o seu retrato íntimo esboçado através da correspondência particular aponta antes como motores do seu labor o interesse econômico e o proselitismo cristão. ${ }^{10}$ Hoje é considerado um agente do imperialismo britânico, um

\footnotetext{
${ }^{8}$ Relation abrégée du voyage que M. Anquetil Du Perron a fait dans l'Inde pour la recherche et la traduction des ouvrages attribués à Zoroastre; Liste des manuscrits déposés à la Bibliothèque du Roi le 15 mars 1762, Paris 1762 (extrato du Journal des Sçavans. jun.jjul. 1762).

${ }^{9}$ À época o método comparativo aplicado às religiões foi bastante polêmico e a incompreensão não tardou em se manifestar: um bispo referiu-se às suas aulas como "a crusade against divine revelation, against Jesus Christ and Christianity". Suas ideias causaram um escândalo tão grande quanto aquele que Darwin tinha provocado com a doutrina evolucionista (A origem das espécies, 1859).

10 "(The Veda) is the root of their religion, and to show them what that root is, is, I feel sure, the only way of uprooting all that has sprung from it during the last 3,000 years." Max Müller. Letter to his Wife. Oxford, December 9, 1867, The Life and Letters of the Right Honourable Friedrich Max Müller. Edited by His Wife, v. 1, London / N.Y.: Longmans, Green, and Co., 1902. p. 328.
} 
profanador de textos que não só não deveriam ter sido traduzidos como não podiam sequer ser conhecidos e pronunciados senão pelos brâmanes. ${ }^{11}$ Não obstante, o aspecto filológico do seu trabalho mantém mesmo assim um prestígio mais duradouro que as suas ideias românticas sobre a origem das religiões. ${ }^{12}$

\section{DAS ACADEMIAS RÉGIAS ÀS SOCIEDADES CIENTíFICAS}

Se o século XVIII assistira à criação das academias de fundação régia que visavam controlar ideologicamente o saber para o porem ao serviço do Absolutismo (ou do despotismo esclarecido), e onde nasceram as primícias do orientalismo, o século XIX, uma época já de claro predomínio burguês, institucionalizou as ciências de forma mais livre através da criação de inúmeras sociedades de geografia, de medicina, de antropologia e de literatura. Estas sociedades savantes ou eruditas eram uma espécie de clubes seletos compostos por sábios e diletantes endinheirados que reuniam a nobreza recente, alguns diplomatas e homens políticos, literatos, naturalistas e cientistas. Uma composição bastante heteróclita e que se devia a que as sociedades não pedissem a todos os seus membros que trabalhassem no domínio científico em ela desenvolvia os seus esforços: muitos eram convidados apenas para gerar boas vontades e simpatia em torno às atividades e objetivos que as sociedades articulavam. No caso das sociedades orientalistas o seu programa era a comparação das línguas, o decifrar das escritas, a descoberta e restauro de monumentos físicos e a tradução de monumentos literários e, igualmente, as belas-letras, a história, a economia, a política e a administração coloniais. Para atingir tais fins as sociedades mantinham uma biblioteca, uma revista periódica, pequenos museus e coleções para estudo.

Totalmente pioneira, a mais antiga sociedade científica orientalista, de cariz colonial, foi criada ainda em finais do século XVIII: a Asiatic Society, fundada em Calcutá em 15 de Janeiro de 1784 e que tinha por objetivo estudar...

(...) the laws of the Hindus and Mahomedans; the history of the ancient world; proofs and illustrations of scripture; traditions concerning the deluge; modern politics and geography of Hindusthan; Arithmatic and Geometry and mixed sciences of Asiaticks; Medicine, Chemistry, Surgery and Anatomy of the Indians; natural products of India; poetry, rhetoric and morality of Asia; music of the Eastern nations; the best accounts of Tibet and Kashmir; trade, manufactures, agriculture and commerce of India: Mughal constitution, Marhatta constitution etc. ${ }^{13}$

A sociedade traçaria em 1847 um plano para a publicação dos Vedas em fascículos de uma coleção intitulada Bibliotheca Indica, que seria editada por filólogos com a ajuda de panditas indianos, o que era já inovação, pois geralmente as sociedades coloniais não

\footnotetext{
${ }^{11}$ Atente-se no subtítulo escolhido por Anquetil-Duperron para a sua tradução latina das Upanishadas: "segredos que não devem ser revelados".

${ }^{12}$ BOSCH. Friedrich Max Müller: A life devoted to the humanities; cf. também http://en.wikipedia.org/ wiki/Max_Müller.

${ }^{13}$ De acordo com o já citado memorandum do seu fundador William Jones.
} 
admitiam os nativos e desprezavam a sua colaboração. Os trabalhos começaram em 1848, iniciados pelos hinos do Rig Veda (RigVeda Samhita) mas foram abortados pela notícia de que Max Müller já estaria preparando sua edição, com tradução inglesa de $\mathrm{H}$. H. Wilson. ${ }^{14}$

As próximas sociedades orientalistas fundadas na Europa serão já todas criadas durante o século XIX: a Société asiatique de Paris foi fundada em 1822 por Antoine-Isaac Silvestre de Sacy, um ano após a também parisiense Société de Géographie. Em Londres foi criada, no ano seguinte, em 1823, a Royal Asiatic Society, pelo sanscritista Henry Colebrooke, que tinha trabalhado na Índia e desejava prosseguir "the investigation of subjects connected with, and for the encouragement of, science, literature and the arts in relation to Ásia", de acordo com o programa da Carta Real, que oficializou a RAS em $1824 .{ }^{15}$ Um pouco mais tarde, em 1842, nascerão na Alemanha a Deutsche Morgenländische Gesellschaft e na América do Norte a American Oriental Society. A Pali Text Society foi fundada 1881 por Thomas Rhys Davids, a quem se chamou o "Max Müller do Budismo", e se destinava a promover a tradução em inglês e edição dos manuscritos theravadin em língua pali para tornar possível o acesso aos canônes do proto-Budismo. Ela iria preparar, com o apoio de monges singaleses - incluindo o auxílio financeiro -, a edição em 56 volumes do Tipitaka. ${ }^{16}$ Childers publicou o primeiro Pali-English Dictionary em 1874 , que foi melhorado pelo de Rhys Davids saído ao público em 1925. ${ }^{17}$

\section{As PRIMEIRAS CÁtedRAS E A CHEGADA AO GRANDE PÚBLICO}

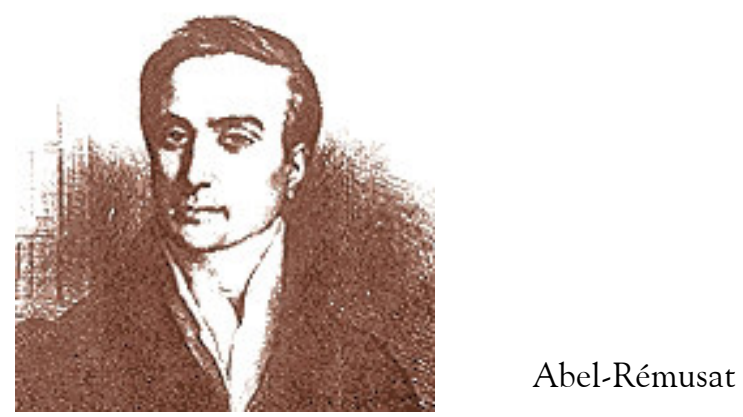

Jean Pierre Abel-Rémusat nasceu em 1788, estando destinado a ser médico como seu pai. Mas em 1806, ao ver uns manuscritos orientais trazidos pelo Abbé de Tersan, passou a dedicar-se com tanto entusiasmo ao estudo das línguas orientais que cinco anos depois, com 23 anos, iniciou sua carreira de orientalista publicando o Essai sur la langue et la littérature chinoises, em Paris, 1811, seguido no mesmo ano pelo Etude des langues étrangères

\footnotetext{
${ }^{14}$ Online em: < http://www.srivaishnava.org/scripts/veda/rv/rvtop.htm >.

${ }^{15}$ A ela pertencerá Rabindranath Tagore, primeiro asiático a receber o Prêmio Nobel de Literatura.

${ }^{16} \mathrm{O}$ Tipitaka, ou Três Cestas, é o mais antigo cânone budista, considerado Buddha-vacana, "a palavra do Buda", embora nele se incluam alguns textos posteriores atribuídos a monges e versando sobre acontecimentos que se seguiram à vida do Buda.

${ }^{17}$ A tradução dos textos sagrados conduziu frequentemente, como no percurso de Max Müller, da gramática comparada ao estudo igualmente comparativo das religiões: Rhys Davids, que ensinou pali na Universidade de Londres de 1882 a 1904, passaria a ensinar Religião Comparada em 1905 na Universidade de Manchester.
} 
chez les Chinois, o que não o impediu de se doutorar em medicina em 1813. Em 1814 foram criadas no Collège de France as duas primeiras cátedras europeias de orientalística, a de sânscrito que teria como primeiro titular Antoine Léonard de Chézy, nascido a 1773, e a de chinês e tártaro-manchu para Abel-Rémusat que se tornou o "príncipe dos sinólogos europeus", e a quem se devem as primeiras traduções de obras confucianas, taoístas e budistas. ${ }^{18}$ Será um dos fundadores em 1822 da Société asiatique de Paris, da qual é o secretário até ocorrer sua morte prematura com a idade de 44 anos. ${ }^{19} \mathrm{Na}$ lição inaugural de Janeiro de 1815 Rémusat classificava assim o universo da literatura chinesa:

Une littérature immense, fruit de quarante siècles d'efforts et de travaux assidus; l'éloquence et la poésie, s'enrichissant des beautés d'une langue pittoresque qui conserve à l'imagination toutes ses couleurs (...): d'un autre côté les Annales les plus vastes et les plus authentiques que nous tenons de la main des hommes, déroulant à nos yeux les actions presque ignorées non seulement des Chinois, mais des Japonais, des Coréens, des Tartares, des Tibétains ou des habitants de la presqu'île ultérieure, ou nous développant les dogmes mystérieux de Bouddha ou ceux des prétendus sectateurs de la Raison, ou consacrant enfin les principes éternels et la philosophie politique de l'école de Confucius: voilà les objets que les livres chinois offrent à l'homme studieux.

Mas será na Alemanha, e não na França, e por via indiana e não chinesa, que o budismo irá conhecer sua entrada triunfal na cultura européia e na filosofia, através de Arthur Schopenhauer. ${ }^{20}$ Ele teve de usar ainda as versões latinas como fonte para o seu O mundo como vontade e representação de 1818, já que as primeiras traduções ocidentais irão ser as alemãs do Lotus Sutra (1852) e do Dhammapada (1862). Por sua vez, austríaco Karl-Friedrich NeumanN traduziu para alemão os principais tratados do cânone pali, ${ }^{21}$ e Hermann Oldenberg divulgou a biografia do Buda em 1881. A publicação em 1879 do poema épico Light of Asia de Edwin Arnold, e em 1922 da novela Siddhartha de Hermann Hesse, popularizaram extraordinariamente o budismo na Alemanha e no Ocidente.

\section{O TRIUNFO DA FILOLOGIA SOBRE A RELIGIÃO}

Renan considerou que "toutes les branches des études philologiques, l'Orient, l'Inde surtout, peuvent offrir pour l'histoire de l'esprit humain les plus précieux de ses données". ${ }^{22}$ A filologia é a "rainha das ciências" e é graças a ela que o mundo moderno é científico:

\footnotetext{
${ }^{18}$ Notas biográficas em: < http://perso.wanadoo.fr/arhfilariane.org/communes/stf_pth/abel_remusat/ remusat_intro.htm $>$. As cátedras universitárias eram tidas como um reconhecimento individual dos

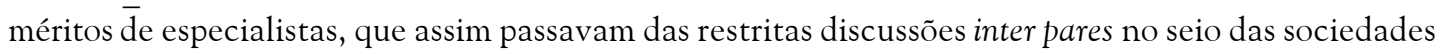
científicas para as instituições de ensino superior onde poderiam suscitar novas vocações e formar discípulos.

${ }^{19}$ No mesmo ano de 1832 tão duro para o Renascimento Oriental, já que nele desapareceram também Champollion, Antoine de Chézy e o armenista Saint-Martin.

${ }^{20}$ MESQUITA. Schopenhauer e o Oriente.

${ }^{21}$ Entretanto também a Ásia reivindicava um lugar nas edições dos textos budistas: na Tailândia, por iniciativa do rei Rama V (Chulalongkorn), foi preparada a edição asiática do cânone em 1893-94.

${ }^{22}$ RENAN. L'avenir de la science: pensées de 1848, p. 109.
} 
Je ne crains pas d'exagérer en disant que la philologie, inséparablement liée à la critique, est un des éléments les plus essentiels de l'esprit moderne, que sans la philologie le monde moderne ne serait pas ce qu'il est, que la philologie constitue la grande différence entre le moyen âge et les temps modernes. Si nous surpassons le moyen âge en netteté, en précision, en critique, nous le devons uniquement à la science philologique. Le moyen âge travaillait autant que nous, le moyen âge a produit des esprits aussi actifs, aussi pénétrants que les nôtres; le moyen âge a eu des philosophes, des savants, des poètes; mais il n'a pas eu de philologues; de là ce manque de critique que le constitue à l'état d'enfance intellectuelle. ${ }^{23}$

Pouco a pouco a antiguidade e o prestígio do sânscrito começou a ultrapassar o das línguas base da cultura europeia, para chegar a ser tido como a língua original e perfeita: "The Sanskrit language, whatever be its antiquity, is of a wonderful structure, more perfect than the Greek, more copious than the Latin and more exquisitely refined than either." 24

Também aos escritores do Novo Mundo chegaram às novas modas filológico-religiosas. Ralph Waldo Emerson escreve:

All my interest is in Marsh's Manu, then Wilkins' Bhagavat Geeta, Burnouf's Bhagavat Purana and Wilson's Vishnu Purana, yes, and few other translations. I remenber I owed my first taste for this fruit to Cousin's sketch, in his first lecture, of the dialogue between Krisna and Arjuna and I still prize the first chapters of the Bhagavast as wonderful. ${ }^{25}$

A orientalística, com suas origens coloniais e imperiais, iria servir afinal para emancipar da herança cristã a intelectualidade ocidental. Conclui-se que os textos védicos eram anteriores ao Antigo Testamento, e descobriu-se nos textos budistas, com grande prioridade, alguns dos temas e ensinamentos morais depois presentes no Novo Testamento.

Estavam ainda para vir as descobertas da nascente ciência assiriológica, quando um dos primeiros assiriólogos, Georges Smith, anunciou em 1872 a descoberta de um relato do dilúvio mais antigo que o da Bíblia nas tabletes cuneiformes, pondo em xeque dentro do próprio mundo semita o mito do "livro mais antigo do mundo" - a Bíblia passava a ser um texto tardio inserido numa longa tradição literária e religiosa que o precedera. Essa tradição podia ser agora estudada nas suas fontes com os mesmos métodos histórico-críticos empregues para qualquer outro texto, antigo ou moderno.

A revolução cultural universalista dos Românticos, suscitada pela leitura dos clássicos orientais, representou a ultrapassagem quer do mundo bíblico quer do clássico, e ocorreu precisamente no momento do apogeu do poderio europeu no mundo: o não europeu entrou vencedor nas fortalezas do pensamento, nas academias, nas universidades, nas escolas filosóficas e literárias. ${ }^{26}$ A Europa se orientalizou no momento em que o Oriente se ocidentalizava. Na filologia o hebreu, o grego e o latim cedem o seu lugar ao avesta e ao sânscrito. Na filosofia a Alemanha descobre uma metafísica aparentada à sua na Índia, que inspiraria o seu pensamento e sua literatura por várias

\footnotetext{
${ }^{23}$ RENAN. L'avenir de la science: pensées de 1848, p. 138-139.

${ }^{24}$ Wiiliam Jones, 3o Discurso Anual da Asiatic Society.

${ }^{25}$ EMERSON R. Journals of Ralph Waldo Emerson, v. 7, 41.

${ }^{26}$ Uma brevíssima resenha da recepção da literatura e cultura indianas no Ocidente pode ser encontrada em S. RADHAKRISHNAN. Eastern Religions $\mathcal{E}$ Western Thougt, p. 247-251.
} 
gerações. Dela nasce a mensagem radicalmente anti-cristã de Nietzsche, que interpreta o Manava Dharma-shastra (Código de Manu) como constituindo o supremo antídoto contra a Bíblia. ${ }^{27}$ Mas sem dúvida a principal herança, para além das querelas religiosas, foi o método comparatista cultivado pelos gramáticos, pelos linguistas e depois pelos mitólogos. E quando a poeira levantada pelo Renascimento Oriental parecia prestes a assentar estavam ainda por descobrir os textos sagrados dos maniqueus e os dos gnósticos que o século XX reencontrou, e que provocaram novos e acalorados debates, ameaçando agora o prestigio do Novo Testamento. Um capítulo de novos-velhos a serem traduzidos e redescobertos, novas pontes textuais unindo mundos separados por séculos de desconhecimento.

\begin{abstract}
A B S TR A C T
The Eastern Sacred texts arrived at Europe during the XVIII and XIX centuries and were supposed to help Christian conversions: proselytizers and missionaries assumed that translating them to European languages would bring to general derision the beliefs of the Eastern colonized nations, and will bring support to the cultural supremacy of the West. However, such translations acted more as a vehicle for Eastern religion to enter the West, rather than to the West to convert the East. The article summarizes the lives of important Orientalists, and presents the first translations of the Persian, Chinese and Indian classics.
\end{abstract}

\title{
KEYWORDS
}

Orientalism, Compared grammar, Translation

\section{REFERÊNCIAS}

BALlANTINE, Tony. Orientalism and Race, Aryanism in the British Empire. New York: Palgrave Macmillan, 2002. 280 p.

BATCHELOR, Stephen. The Awakening of the West, The Encounter of Buddhism and Western Culture. Berkeley: Parallax Press, 1994. 418 p.

BAUMANN, Martin. Buddhism in Europe, An Annotated Bibliography. Disponível em: < http://www.globalbuddhism.org/bib-bud.html>. Acesso em: 19 fev. 2009.

BOSCH, Lourens van den. Friedrich Max Müller: A Life Devoted to the Humanities. Leiden: Brill, 579; cf. também http://en.wikipedia.org/wiki/Max_Müller.

CHEN, Joseph; JINGPAN, Chen. Confucius as a Teacher. Beijing: Foreign Languages Press, 1994. 522 p.

EMERSON, R. Journals of Ralph Waldo Emerson. Boston 1909-1914 (vários volumes).

${ }^{27}$ NIETZSCHE. Der Antichrist. 1895. caps. 56-57. Sobre N. e o orientalismo veja-se ROLLMANN. Deussen, Nietzsche, and Vedanta. 
HALBFASS, Wilhelm. India and Europe: An Essay in understanding. New York: Suny, 1988. $604 \mathrm{p}$.

HARE, John. Internet Sacred Text Archive. Disponível em: < http://www.sacredtexts.com>. Acesso em: 19 fev. 2009.

JONES, William. 3o Discurso Anual da Asiatic Society. Apud, inter alia, T. BURROW, Sanskrit Language. New Delhi: Motilal Banarsidas, 2001, (438), 6; cf. também http:// en.wikipedia.org/wiki/Sir_William_Jones.

KING, Richard. Orientalism and Religion, Postcolonial Theory, India and "The Mythic East". London: Routledge, 1999. 296 p.

MESQUITA. Schopenhauer e o Oriente. São Paulo: USP, 2007. 159 p. Disponível em: $<$ http://www.teses.usp.br/teses/disponiveis/8/8133/tde-07022008-110708/>. Acesso em: 19 fev. 2009.

NIETZSCHE, Friedrich. Der Antichrist. Leipzig: Naumann, 1894.

QUINET, Edgar. De la renaissance orientale (1841). Paris: L'Archange Minotaure, 2003. 60 p.

RADHAKRISHNAN S. Eastern Religions $\mathcal{E}$ Western Thougt. New York: Oxford University Press, 1990. 396 p.

RENAN, Ernest. L'avenir de la science: pensées de 1848. Paris: Flammarion, 542.

ROLLMANN, Hans. Deussen, Nietzsche, and Vedanta. Journal of the History of Ideas, 39, 1. 1978, 125-132.

SCHWAB, Raymond. La Renaissance orientale: La découverte du sanscrit, le siècle des écritures déchiffrées, l'avènement de l'humanisme intégral, grandes figures d'orientalistes. Paris: Payot, 1950. 526 p.

SMITH, Mahlon. Virtual Religion Index. http://virtualreligion.net/vri/.

UNIVERSIDADE DE BONA. Indology past and present. Disponível em: < http:// www.indologie.uni-bonn.de/Einleitung_en.html>. Acesso em: 19 fev. 2009.

YOUNG, R. F. \& S. JEBANESAN. The Bible Trembled, The Hindu-Christian Controversies of Nineteenth-Century Ceylon. Vienna: De Nobili Research Library, 1995. 204 p. 